\title{
The New Measurement Method of Blending Ratio of PTT/PET Fiber Blends by Centrifugal Separation
}

\author{
Yingzhu $\mathrm{Wu}^{1, \mathrm{a}^{*}}$, Hushui $\mathrm{Ye}^{3, \mathrm{~b}}$, Xiaoli Zhang ${ }^{3, \mathrm{c}}$, Chen $\mathrm{Li}^{2, \mathrm{~d}}$, Meilin Huang ${ }^{1, \mathrm{e}}$, \\ Xingqing Feng ${ }^{1, ~} f$ \\ ${ }^{1}$ School of Textile and Clothing, Wuyi University, Jiangmen,Guangdong Province,China \\ ${ }^{2}$ School of Chemical and Environmental Eningeering Wuyi University, Jiangmen,Guangdong \\ Province, China \\ ${ }^{3}$ Guangdong Inspection and Quarantine Technology Center, Guangzhou, Guangdong Province, \\ China
}
awuyingzhu111@163.com, byehsh@iqtc.cn; 'zhangx|@iqtc.cn; 'simmonlee@163.com; e14517465@qq.com; 564166700@qq.com

Keywords: PTT (polytrimethylene-tereph-thalate) fiber, PET ( polyethylene terephthalate) fiber, blending ratio, quantitative analysis, centrifugal separation.

Abstract: The PTT fiber is one of the elastic polyester fibers Owing to the similar physical and chemical properties of PTT fiber and PET fiber, the current testing standard methods are difficult to measure their blending ratios. According to the density of PTT $\left(1.33 \mathrm{~g} / \mathrm{cm}^{3}\right)$ is slightly lower than PET $\left(1.38 \mathrm{~g} / \mathrm{cm}^{3}\right)$, so the density difference of these two fibers has been used to develop a new quantitative measurement method here. In this work, a mixture liquid with certain densities were made by mixing with different ratio of xylene and carbon tetrachloride, then the samples of PET/PTT blending fiber were put into the liquid. Finally, the two kinds of fibers were well separated by using the centrifugal force, and their blending ratios were accurately determined. Optimal centrifugal separation process was obtained: the blending fiber was cut into powder, centrifugal speed was set at $800 \mathrm{r} / \mathrm{min}$; centrifugal time was 5 minutes; solid-liquid ratio was $0.04: 35(\mathrm{~g} / \mathrm{mL})$. This simple separation method could be used to determine the blending ratios of other special fibers, and the automatic measurement technology would be promoted forward.

\section{Introduction}

The PET (polyethylene terephthalate) fiber is the world's largest output and widely used in textile industry $^{[1]}$. The PTT (polytrimethylene-tereph-thalate) fiber is one of the new polyester fibers. The densities of PET and PTT are 1.38 and $1.33 \mathrm{~g} / \mathrm{cm}^{3}$, respectively. The latter has good acid and alkali resistance just like the former, and also good flexibility like polyamide fiber, and good elasticity like spandex. So the PTT fiber has been more and more applied in the textile and garment industry. ${ }^{[2-3]}$<smiles>CC(C)(C)OC(=O)c1ccc(C(=O)OCCCC(C)(C)C(C)(C)OC(=O)c2ccc(C(=O)OCCCC(I)(I)I)cc2)cc1</smiles>

Fig. 1 The molecular structure of PET (on left) and PTT (on right)

Fig. 1 showed that the difference of these two fibers is only one methylene group in the structural unit of PTT molecular than PET molecular. That means that they have very similar physical and chemical properties. The current testing standards only can qualitatively identify them, but difficult to quantitatively determine their blending ratio. The DSC (differential scanning calorimetry) instrument was used to determine PET/PTT blending ratio in recent studies, such as the identification of three polyester fibers PET, PTT and PBT by DSC, combined with NMR (Nuclear Magnetic Resonance) instrument to measure their blending ratio. ${ }^{[4-5]}$. However, these methods have the disadvantages: the equipment was expensive and complicated to operate, these methods are difficult to widely used. So it is very necessary and important to develop a quantitative determination method for the similar polyester fibers, with general-purpose device and simple operating. As discussed above, considering of 
the slightly difference of the densities between PTT and PET fiber, a centrifugal separation method was proceeded by our research group ${ }^{[6]}$.

\section{Experiment}

\section{Main instruments and materials}

Main instruments: JA5003A electronic balance (Shanghai JingTian), circulating water pump, TDL-40B centrifuge instrument, Hastelloy slicer.

Materials: White PTT filament yarn, PET sewing thread made by staple fiber, carbon tetrachloride, and xylene.

\section{Determine of fiber blending ratio by centrifugal separation method}

The PET fiber and PTT fiber blending samples were cut into several millimeters and dried. The preparation of mixed solutions with densities between $1.33 \sim 1.38 \mathrm{~g} / \mathrm{cm}^{3}$ were obtained by mixing of different ratio of xylene $\left(0.857 \mathrm{~g} / \mathrm{cm}^{3}\right)$ and carbon tetrachloride $\left(1.572 \mathrm{~g} / \mathrm{cm}^{3}\right)$. The mixed fiber samples were degassed to be sufficient wet in the mixed solution, and then were added into the centrifuge tubes, which were filled with a certain amount of centrifugal liquid. Then, the PET fibers and PTT fibers were separated at a certain centrifugation speed after several minutes. The PTT fibers floated onto the top of the mixed solution, and the PET fibers sank down to the bottom, respectively. After filtering, the two fibers were dried and weighed, and finally their corresponding percentages were calculated.

\section{Results and discussion}

\section{The effect of liquid density on centrifugal separation}

Three mixed solutions with density of $1.36 \mathrm{~g} / \mathrm{cm}^{3}, 1.37 \mathrm{~g} / \mathrm{cm}^{3}, 1.38 \mathrm{~g} / \mathrm{cm}^{3}$ were respectively prepared using xylene and carbon tetrachloride. Fifteen milliliters of each solution was added into three centrifuge tubes, respectively. After degassing, two fiber balls, including one big PTT fiber ball and another small PET fiber ball, were put into one centrifugal tube. After standing stay for one hour, the same phenomena appeared in the three centrifugal tubes as shown in Fig. 2, the big PTT fiber ball was floating on top of solution; the small PET fiber ball was sinking on the bottom. The separation effect was very good. PET fibers and PTT fibers could be quickly identified. Therefore, further experiments were adopted at the density of $1.36 \mathrm{~g} / \mathrm{cm}^{3}$ as centrifugal fluid.

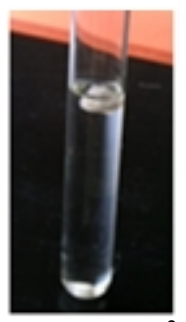

$1.36 \mathrm{~g} / \mathrm{cm}^{3}$

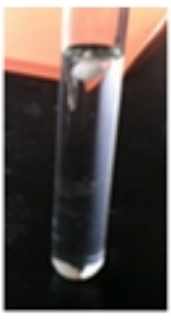

$1.37 \mathrm{~g} / \mathrm{cm}^{3} 1.38 \mathrm{~g} / \mathrm{cm}^{3}$

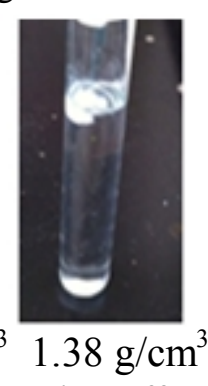

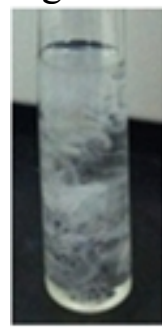

$10 \mathrm{~mm}$

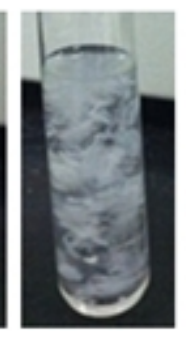

$5 \mathrm{~mm}$

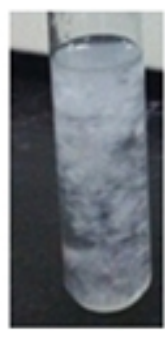

$2 \mathrm{~mm}$ fiber power

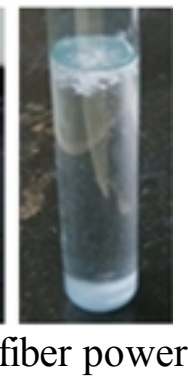

Fig. 2 Liquid density on separation effect Fig. 3 Fiber length on separation effect

\section{The effect of fiber length on centrifugal separation}

As shown in Fig. 3, under the same conditions, with the increase of fiber length, separation effect of PET/PTT mixed fiber samples deteriorated. The reason could be explained that the longer the length of the fiber, the more be entangled and squeezed of PET and PTT fibers into together. Which may result the PTT fiber ball difficult to float up, meanwhile, PET fiber was difficult to sink. Therefore, when the fiber was cut into powder, the mixed samples had small extrusion between each other, and better separation effect was obtained.

\section{The effect of diameter of tube on centrifugal separation}

As shown in Fig. 4, under the same experimental conditions, the larger the tube diameter, the more obvious the separation effect. The diameter of container was chosen as $15 \mathrm{~mm}, 20 \mathrm{~mm}$ and 34 
$\mathrm{mm}$, respectively. The static separation time was 14 hours, 8 hours and 2 hours, respectively. The reason could be that the larger the diameter, the more loose the PET and PTT fiber powder. Meanwhile, during the separation process, the probability of collision with each other became lower, which ensures that the two kinds of fibers could be rapidly separated. Therefore, the succeeding experiments had used the large-diameter tube as centrifugal tube.

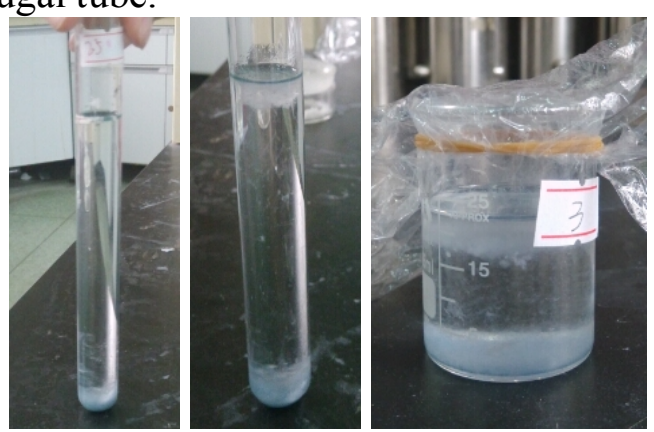

Fig. 4 Tube diameter on the separation effect

\section{The effect of solid-liquid ratio on centrifugal separation}

To study the optimal solid-liquid ratio, every mixed fiber sample was weighted $0.04 \mathrm{~g}$, and the volume of mixed solutions was $25 \mathrm{~mL}, 30 \mathrm{~mL}$ and $35 \mathrm{~mL}$, respectively. The prepared standard fiber sample of PET/PTT had the mixing ratio of 50/50. As shown in Table 1, the larger volume of solution, the smaller the error, and the longer the separation time. Considering detecting error and separation effect, the optimal solid-liquid ratio was chosen as 0.04:35 $(\mathrm{g} / \mathrm{mL})$.

Table 1 The solid-liquid ratio on separation effect

\begin{tabular}{cccccc}
\hline \multirow{2}{*}{$\begin{array}{c}\text { volume } \\
(\mathrm{mL})\end{array}$} & \multicolumn{2}{c}{ True Percentage $(\%)$} & \multicolumn{2}{c}{ Testing Percentage $(\%)$} & Error \\
\cline { 2 - 5 } & PET & PTT & PET & PTT & $(\%)$ \\
\hline 25 & 50 & 50 & 53.9 & 46.2 & 3.9 \\
30 & 50 & 50 & 52.3 & 47.7 & 2.3 \\
35 & 50 & 50 & 51.5 & 48.4 & 1.6 \\
\hline
\end{tabular}

\section{The effect of centrifuge speed on centrifugal separation}

The result showed that the centrifugal speed was an important factor, affecting the separation effect of PET/PTT mixed fibers. Under the same experimental conditions: PET/PTT mixed ratio was 50/50, mixed fiber was cut into powder, centrifugation time was 5 minutes, and the impact of speed on centrifugal separation was compared. As shown in Table 2, the greater the centrifugal speed, the greater the centrifugal force, and the better the separation effect. The results showed that the better centrifugal speed was $800 \mathrm{r} / \mathrm{min}$. When the speed was more than $1000 \mathrm{r} / \mathrm{min}$, the mixed solution would be stratified into two kinds of solution, which causing separation effect became worse.

Table 2 The centrifuge speed on separation effect

\begin{tabular}{|c|c|c|c|c|c|}
\hline \multirow{2}{*}{$\begin{array}{c}\text { Speed } \\
(\mathrm{r} / \mathrm{min})\end{array}$} & \multicolumn{2}{|c|}{ True Percentage (\%) } & \multicolumn{2}{|c|}{ Testing Percentage (\%) } & \multirow{2}{*}{$\begin{array}{c}\text { Error } \\
(\%)\end{array}$} \\
\hline & PET & PTT & PET & PTT & \\
\hline 800 & 50 & 50 & 50 & 50 & 0 \\
\hline 800 & 50 & 50 & 51.1 & 49.2 & 1.1 \\
\hline 500 & 50 & 50 & 54.3 & 45.5 & 4.5 \\
\hline 500 & 50 & 50 & 53.7 & 46.3 & 3.7 \\
\hline
\end{tabular}

\section{The effect of centrifuge time on centrifugal separation}

The result showed that the centrifugal time was another important factor affecting the separation effect of PET/PTT mixed fibers. Under the same experimental conditions: PET/PTT mixed ratio was $50 / 50$, mixed fiber was cut into powder, centrifugation speed was set at $800 \mathrm{r} / \mathrm{min}$, and the impact of centrifugal time on centrifugal separation effect was examined. As shown in Table 3, the centrifugal 
separation effect was better after five minutes. However, the separation effect was worse after ten minutes for the reason that if the centrifugal time was too long, the mixed solution may be stratified into two kinds of solutions.

Table 3 The centrifugation time on separation effect

\begin{tabular}{cccccc}
\hline \multirow{2}{*}{$\begin{array}{c}\text { Time } \\
\text { (minute) }\end{array}$} & \multicolumn{2}{c}{ True Percentage (\%) } & \multicolumn{2}{c}{ Testing Percentage (\%) } & \multirow{2}{*}{ Error (\%) } \\
\cline { 2 - 5 } & PET & PTT & PET & PTT & \\
\hline 3 & 50 & 50 & 53.7 & 46.3 & 3.7 \\
3 & 50 & 50 & 53.2 & 46.6 & 3.4 \\
5 & 50 & 50 & 52.1 & 47.8 & 2.2 \\
5 & 50 & 50 & 51.6 & 48.2 & 1.8 \\
10 & 50 & 50 & 54.2 & 46.0 & 4.0 \\
10 & 50 & 50 & 54.6 & 45.5 & 4.6 \\
\hline
\end{tabular}

\section{Conclusion}

(1) The centrifugal separation method presented in this work was able to accurately determine the blending ratio of PTT/PET mixed fiber, and the testing accuracy met the requirements of textile industrial standards.

(2) The optimum process of determination was as follows: the density of mixed solution was 1.36 $\mathrm{g} / \mathrm{cm}^{3}$; the fiber was cut into powder; the centrifugal speed was set at $800 \mathrm{r} / \mathrm{min}$; the centrifugation time was 5 minutes; the solid-liquid ratio was $0.04: 35(\mathrm{~g} / \mathrm{ml})$.

(3) Currently, the blending ratios of viscose/modal fiber blends, rayon/bamboo fiber blends and other cellulose fibers blended products were very difficult to determine. The centrifugal separation method proposed in this work could be regards as a very valuable reference and a new way for solving these difficult problems.

\section{Acknowledgements}

The authors gratefully acknowledge the financial support provided by Guangdong Entry-Exit Inspection and Quarantine industry standard formulate (revise) Project (2014B028), Guangdong Inspection and Quarantine Technology Project (2015GDK62), Wuyi University Youth Teacher Fund (2014ZK16), Guangdong Province Education Department Features Innovation Project (2014KTSCX135).

\section{References}

[1] WANG Jingli, ZHU Junyan, ZHAO Zhenyu, et al. Study on homogeneity of textile fiber sample by use of sample fiber near infrared spectroscopy detection. Shang Hai Textile Science \& Technology,2013, 41(11):4-7 (In Chinese)

[2] KIIBLER KS, KELSEY DR, TUTUNJIAN PN. Thermal Stability of Poly(Trimethylene Terephthalate). Polymer, 2005, 46 (21): 8937-8946

[3] CASTELLANO M, TURTURRO A, VALENTI B, et al. Reactive Blending of Aromatic Polyesters: Thermal Behaviour of Co-Precipitated Mixtures PTT/PET. Macromolecular Chemistry and Physics, 2006, 207 (2): 242-251

[4] NI Y, LIU Z, HU T, et al. Qualitative and Quantitative Analysis of PET,PTT and PBT Materials. Journal of Textile Research, 2012, 33 (10): 28-32 (In Chinese)

[5] ZHANG Wen-Hui YUAN Chuan-gang. Study on the method to identify PTT fiber and PET fiber, Shang Hai Textile Science \& Technology.2009,37(7):17-18 (In Chinese)

[6] LIU Yuwen, Ye Hushui, WU Yingzhu*, et al. A New Quantitative Analysis Method for Determining Two Components Fabrics Blending ratio via Centrifugal Separation. Shang Hai Textile Science \& Technology, 2015,43(5):54-57 (In Chinese) 